\title{
In vitro fertilization and embryo development in the marmoset monkey (Callithrix jacchus)
}

\author{
L. J. Wilton*, V. S. Marshall, E. C. Piercy and H. D. M. Moore $\dagger$ \\ Institute of Zoology, Regent's Park, London, NW1 4RY, UK
}

\begin{abstract}
Oocytes aspirated from preovulatory (i.e. $\geq 2 \mathrm{~mm}$ ) follicles of marmoset monkeys were graded for maturity according to the degree of cumulus expansion, grade I being most mature and grade IV least mature. After preincubation for $2-5,9-11$ or $21-29 \mathrm{~h}, 82 \%$ of oocytes could be fertilized using epididymal spermatozoa and only $2.3 \%$ were polyspermic. Fertilization rate was lowest $(60 \%)$ in grade IV oocytes and all oocytes preincubated for $2-5 \mathrm{~h}(53 \%)$. Fertilization rate increased to $92 \%$ in oocytes preincubated for $21-29 \mathrm{~h}$. Embryos developed in vitro to a mean of eight cells. Embryo development was unaffected by oocyte maturity but correlated with preincubation time. Oocytes preincubated for $2-5 \mathrm{~h}$ developed into embryos with significantly fewer cells than those preincubated for 9-11 or 21-29 h $(P<0.001)$. Fifty-six per cent of embryos showed delayed cleavage and these had fewer cells than non-delayed embryos $(P<0.001)$. When oocytes were preincubated for 2-5 h, development of all resulting embryos was delayed. However, only 17 and $58 \%$ of embryos developing from oocytes preincubated for 9-11 and 21-29 h, respectively, were delayed and this was independent of oocyte maturity.
\end{abstract}

Introduction

In recent years in vitro fertilization (IVF) has provided access to human preimplantation embryos. Research studies on human embryos have increased our knowledge of early human development but for ethical reasons an empirical approach has had to be adopted. This precludes detailed investigations over the peri-implantation period so crucial for embryo development. For this reason, we must rely on non-human primate models to investigate pre- and postimplantation development fully. IVF systems have been developed for rhesus monkeys (Bavister et al., 1983; Boatman et al., 1986; Wolf et al., 1989; Morgan et al., 1990), squirrel monkeys (Dukelow et al., 1983), cynomolgus monkeys (Balmaceda et al., 1984), baboons (Irsigler et al., 1984) and chimpanzees (Gould, 1983) with varying degrees of success. In particular, in vitro culture of embryos produced by IVF has been difficult in all non-human primate species (see Boatman, 1987). In this laboratory the common marmoset (Callithrix jacchus) has been successfully used for IVF and embryo transfer (Summers et al., 1987; Lopata et al., 1988) and a small number of embryos have been cultured in vitro (Lopata et al., 1988). In the present study we have set out to improve marmoset IVF by optimizing the timing of follicular aspiration and insemination and have demonstrated significant effects on embryo development in vitro. As well as aiding our knowledge of preimplantation primate development, these techniques could also be applied to captive breeding of closely related endangered species such as the golden lion tamarin (Leontopithecus rosalia).

*Present address: Centre for Early Human Development, Monash Medical Centre, Clayton, Victoria, Australia 3168.

†Present address: Department of Molecular Biology and Biotechnology, University of Sheffield, Western Bank, Sheffield S10 2UH, UK.

Received 22 April 1992.

\section{Materials and Methods}

\section{Animals}

Adult female marmoset monkeys (Callithrix jacchus) of proven fertility were housed with their male partners. All females in our colony are routinely monitored to determine the day of ovulation by measuring plasma progesterone concentrations using an enzyme-linked immunoassay (Hodges et al., 1988) in $0.3 \mathrm{ml}$ of blood collected from the femoral vein. In the females used in this study, premature luteolysis was induced by an injection of $0.5 \mu \mathrm{g}$ of cloprostenol, an analogue of prostaglandin $\mathrm{F}_{2 \alpha}$ (Estrumate: ICl, Macclesfield) at 09:00 h between 13 and 22 days after the previous ovulation (Summers et al., 1985). At 13:00 h on day 7 after cloprostenol treatment, animals were given an injection of 75 iu of human chorionic gonadotrophin (hCG; Chorulon: Intervet Laboratories, Cambridge). A total of 41 ovarian cycles were investigated in 36 marmosets. There was an interval of 4-13 months between investigations in the five animals that were used twice.

\section{Follicular aspiration and oocyte recovery}

Oocytes were surgically collected 21-24 h after hCG injection. Animals were anaesthetized and the ovaries and uterus exposed by a mid-line laparotomy. Only follicles greater than $2 \mathrm{~mm}$, and hence defined as preovulatory (Harlow et al., 1988), were aspirated. An aspiration pipette was prepared by pulling a $1.5 \mathrm{~mm}$ diameter thin-walled glass capillary (Clark Electromedical, Reading) over a flame and then breaking it at a diameter of $0.7-0.8 \mathrm{~mm}$. Follicular puncture was facilitated by a sharp spike on the pipette that was produced by touching the tip on the 


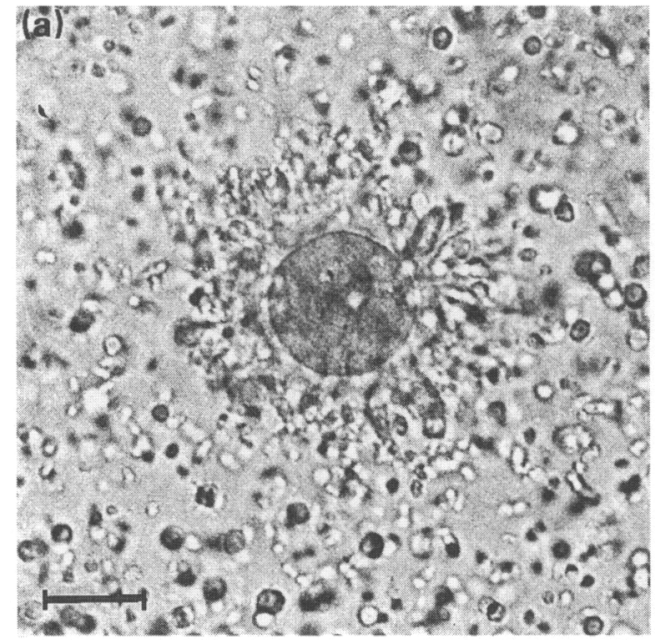

(c)

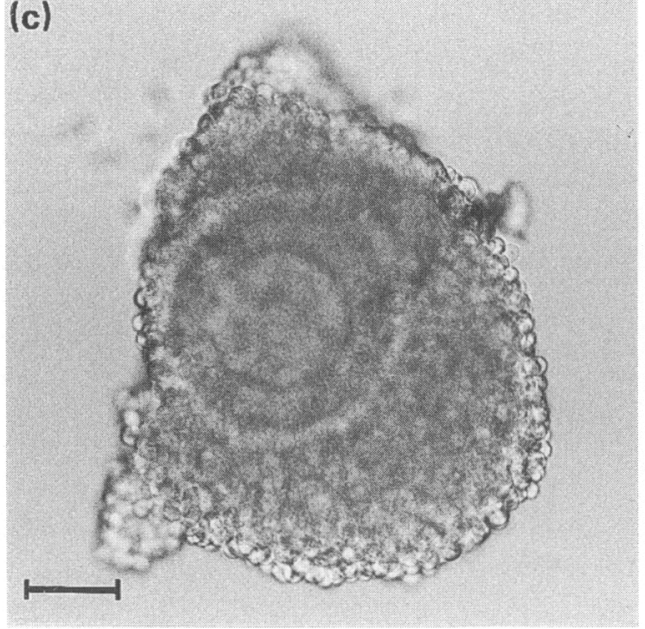

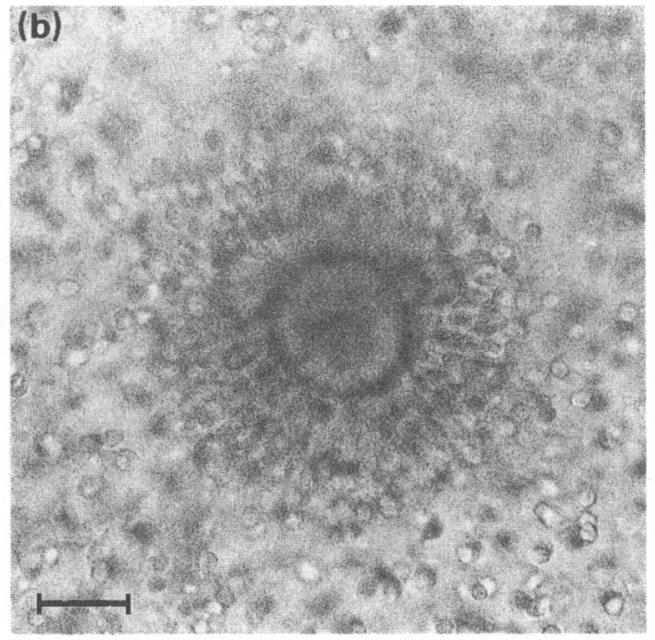

(d)

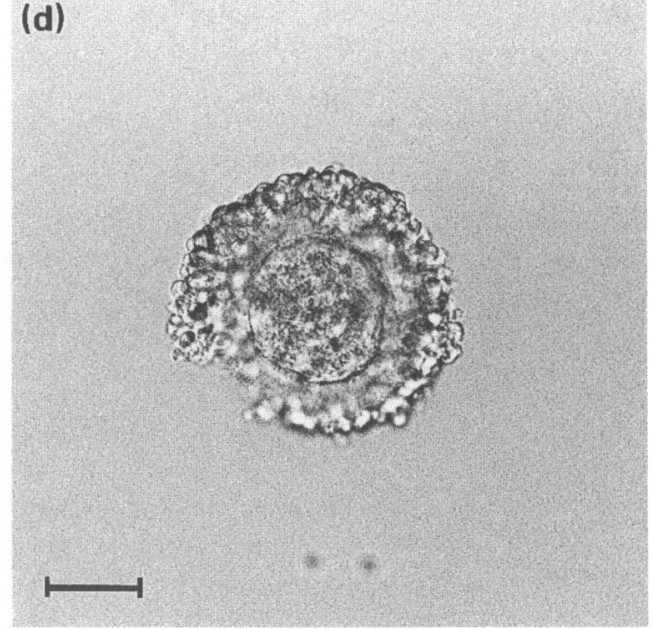

Fig. 1. Marmoset oocytes at different stages of maturation. (a) Grade I - well expanded cumulus cells; (b) grade II - extensive cumulus cells that are not fully expanded; (c) grade III - several layers of non-expanded cumulus cells; (d) grade IV - only a few layers of tightly packed cumulus cells. Bars $=50 \mu \mathrm{m}$.

heated glass bead of a microforge. The pipette was attached to a micrometer syringe which enabled controlled suction of the follicle. Follicular contents were expelled into alpha-modified minimum essential medium (MEM; Gibco, Uxbridge) buffered with $25 \mathrm{mmol}$ Hepes $\mathrm{I}^{-1}$ and containing $1 \%$ heat-inactivated marmoset serum, $5 \mathrm{mg}$ streptomycin sulfate $(100 \mathrm{ml})^{-1}, 6 \mathrm{mg}$ penicillin $(100 \mathrm{ml})^{-1}$ and 1 iu heparin $\mathrm{ml}^{-1}$. It was not possible to visualize extrusion of the first polar body through the cumulus cells and oocytes were therefore scored for maturity according to degree of cumulus expansion. Grade I oocytes had extensive, well-expanded cumulus; grade II oocytes had several layers of cumulus cells that were not fully expanded; grade III oocytes had several layers of densely packed cumulus cells and grade IV oocytes had only 2-3 layers of tightly packed surrounding cells (Fig. 1).

Before insemination, oocytes were preincubated in MEM containing $10 \mu \mathrm{mol}$ dibutyryl cAMP $1^{-1}, 10 \mu \mathrm{mol}$ caffeine $\mathrm{I}^{-1}, 5 \mathrm{mg}$ streptomycin sulfate $(100 \mathrm{ml})^{-1}, 6 \mathrm{mg}$ penicillin $(100 \mathrm{~mol})^{-1}$ and $10 \%$ marmoset serum for $2-5,9-11$ or $21-$ $29 \mathrm{~h}$ at $37^{\circ} \mathrm{C}$ in an atmosphere of $5 \% \mathrm{CO}_{2}$ in air or, in later experiments, $5 \% \mathrm{CO}_{2}, 5 \% \mathrm{O}_{2}$ and $90 \% \mathrm{~N}_{2}$, although this made no difference to the results.

\section{Preparation of spermatozoa}

Preliminary work demonstrated that very few spermatozoa collected by electroejaculation could be separated from the seminal secretions that coagulated immediately on collection and resisted all attempts at liquefaction or separation. Moreover, the few spermatozoa that were free swimming were extremely sensitive even to gentle centrifugation and had poor motility and viability, surviving less than $8 \mathrm{~h}$ in vitro. In contrast, epididymal spermatozoa were highly motile and survived for more than $48 \mathrm{~h}$ in vitro in media containing marmoset serum. Marmoset spermatozoa whether epididymal or electroejaculated survived for less than $6 \mathrm{~h}$ in media supplemented with fetal calf serum (data not shown). Consequently epididymal spermatozoa were used for all the experiments described here.

The epididymides were carefully dissected from male marmosets of proven fertility and coarsely minced in MEM 
containing dibutyryl cAMP, caffeine, antibiotics and 10\% marmoset serum as for oocyte preincubation.

\section{In vitro fertilization and embryo culture}

Spermatozoa were diluted to a concentration of between 5 and $10 \times 10^{5} \mathrm{ml}^{-1}$ and oocytes added for 6-8 h. In some experiments, immature oocytes were inseminated for $12-22 \mathrm{~h}$. Oocytes were then washed and incubated in MEM plus $10 \%$ marmoset serum and insulin-transferrin-sodium selenium supplement (Lopata et al., 1988) for $4-20 \mathrm{~h}$ after which time in most cases the cumulus had migrated away from the zona pellucida. If this failed to occur, oocytes were gently aspirated through a flame polished pipette to dislodge the cumulus cells.

Fertilization was confirmed by visualizing the clearly distinguishable pronuclei using an inverted microscope fitted with differential interference contrast optics. In most cases two polar bodies could also be identified. Embryos were cultured in MEM supplemented with $10 \%$ marmoset serum at $37^{\circ} \mathrm{C}$ in $5 \% \mathrm{CO}_{2}$ in air or, in later experiments, in a mixture of $5 \% \mathrm{CO}_{2}, 5 \% \mathrm{O}_{2}$ and $90 \% \mathrm{~N}_{2}$, although this made no difference to the results. Embryos were considered to have arrested if no cells had cleaved within the previous $48 \mathrm{~h}$.

\section{Statistical analyses}

Fertilization rates were compared using a $\chi^{2}$ or $V^{2}$ (when sample size was less than 10) test. Student's $t$ tests were used to compare mean cell number of embryos. The level of significance was $P<0.05$.

\section{Results}

Follicular development was successfully controlled so that in 40 of 41 surgical procedures, pre-ovulatory follicles (i.e. $>2 \mathrm{~mm}$ ) were present and no animal had ovulated at the time of laparotomy. In the 41 laparotomies, there were 110 pre-ovulatory follicles, a mean of 2.7 follicles per animal. All follicles were aspirated and 88 of $110(80 \%)$ oocytes were recovered overall. However, in the 26 most recent laparotomies 62 of 67 (93\%) of oocytes were recovered. Of the 88 oocytes recovered $19(22 \%)$, $36(41 \%), 19(22 \%), 13(15 \%)$, and $1(1 \%)$ were grade I, II, III, IV and atretic, respectively.

One grade III, three grade IV and the atretic oocyte were not inseminated. Eighty-three oocytes were inseminated and 68 (82\%) fertilized. Two $(2.3 \%)$ of these were polyspermic, confirmed by the presence of three pronuclei. Fertilization rate was dependent on oocyte maturity. Grade IV oocytes had a fertilization rate of $60 \%$, whereas $78-92 \%$ of grade I-III oocytes fertilized (Table 1). Fertilization rate also depended upon the duration of oocyte incubation before insemination (preincubation). As shown in Table 1, oocytes preincubated for $2-5 \mathrm{~h} \mathrm{had}$ a fertilization rate of $53 \%$ (10 of 19 ). This increased to $86 \%$ (12 of $14, P<0.002$ ) and remained high at $92 \%$ (46 of 50) after $9-11$ and $21-29 \mathrm{~h}$ oocyte preincubation, respectively. The effect of longer preincubation of oocytes on fertilization rate was most marked in least mature oocytes. Although the numbers in these groups were small, fertilization appeared to be
Table 1. Fertilization rate (\%) of marmoset oocytes of grades I-IV after preincubation for $2-5,9-11$ or $21-29 \mathrm{~h}$

\begin{tabular}{lccccccc}
\hline & \multicolumn{5}{c}{ Duration of preincubation (h) } \\
Oocyte \\
\cline { 2 - 7 } grade & $2-5$ & \multicolumn{2}{c}{$9-11$} & $21-29$ & Total \\
\hline & & & & & \\
I & $2 / 5$ & $(40)$ & $2 / 2$ & $(100)$ & $11 / 12^{*}$ & $(92)^{\mathrm{a}}$ & $15 / 19(79)$ \\
II & $7 / 9$ & $(78)$ & $7 / 7$ & $(100)$ & $19 / 20^{*}$ & $(95)$ & $33 / 36(92)$ \\
III & $1 / 4$ & $(25)$ & $2 / 3$ & $(67)$ & $11 / 11$ & $(100)^{\mathrm{b}}$ & $14 / 18(78)$ \\
IV & $0 / 1$ & $(0)$ & $1 / 2$ & $(50)$ & $5 / 7$ & $(71)$ & $6 / 10(60)$ \\
Total & $10 / 19(53)$ & $12 / 14$ & $(86)^{\mathrm{c}}$ & $46 / 50$ & $(92)^{\mathrm{c}}$ & $68 / 83(82)$ \\
& & & & & & & \\
\hline
\end{tabular}

${ }^{*}$ Includes one polyspermic fertilization.

${ }^{a} P<0.025$ compared with grade I oocytes preincubated for $2-5 \mathrm{~h}$.

${ }^{b} p<0.002$ compared with grade III oocytes preincubated for $2-5 \mathrm{~h}$.

c $P<0.002$ compared with all oocytes preincubated for $2-5 \mathrm{~h}$.

improved with longer preincubation. Only one out of three grade IV oocytes incubated for $2-5$ or 9-11 h fertilized. However, 5 of 7 (71\%) grade IV oocytes fertilized after $21-29 \mathrm{~h}$ preincubation (Table 1). Similarly, the fertilization rate of grade III oocytes increased from 25 to 67 and $100 \%(P<0.002)$ by increasing the preincubation time from $2-5 \mathrm{~h}$ to $9-11$ and 21-29h, respectively (Table 1 ). The fertilization rate of grade I and II oocytes increased to $100 \%$ after $9-11 \mathrm{~h}$ preincubation and remained high when oocytes were preincubated for $21-29 \mathrm{~h}$ $(P<0.025)$.

Of the 66 normally fertilized embryos, $60(91 \%)$ cleaved to two cells. One embryo was inadvertently lost at the two-cell stage. Fifty-three $(82 \%)$ of the remaining 65 embryos reached the four-cell stage and $31(48 \%)$ divided to eight cells. Of these, seven (11\%) cleaved to 16 cells and began to compact. Only one embryo reached the 32-cell stage. Overall, the mean ( \pm SEM) maximum cell number reached for normally fertilized embryos was $7.7 \pm 0.7$ (Table 2). The two triploid embryos divided to six and 12 cells. When data from all preincubation times were combined, there was no significant difference in the mean maximum cell number between the embryos produced from different grade oocytes (Table 2).

However, increasing the duration of oocyte preincubation had a beneficial effect on embryo development. Forty per cent (4 of 10) of oocytes preincubated for only $2-5 \mathrm{~h}$ failed to cleave and none developed further than six cells (Fig. 2). However, only 2 of $52(3.8 \%)$ of oocytes preincubated for $9-11$ or $21-29 \mathrm{~h}$ failed to cleave and a total of 29 of $52(56 \%)$ of these oocytes reached at least the eight-cell stage (Fig. 2). This was also reflected in the mean maximum cell number. Oocytes preincubated for $2-5 \mathrm{~h}$ developed into embryos with mean maximum cell number of $2.8 \pm 0.7$ and oocytes preincubated for 9-11 and 21-29 h cleaved to a mean maximum cell number of $9.6 \pm 2.5(P<0.001)$ and $8.3 \pm 0.6(P<0.001)$, respectively (Table 2 and Fig. 2). This effect was most marked in grade II oocytes. The mean maximum cell number significantly increased from $2.3 \pm 0.6$ to $13.7 \pm 3.4(P<0.001)$ after grade II oocytes were preincubated for $9-11 \mathrm{~h}$ and to $9.4 \pm 1.0$ $(P<0.001)$ after $21-29 \mathrm{~h}$ preincubation.

Marmoset embryos should reach the four-cell stage on day 2 after insemination (Harlow, 1984). In the present study, 35 of 
Table 2. Mean + SEM maximum cell number of marmoset embryos developing from grades I-IV oocytes preincubated for $2-5,9-11$ or $21-29 h^{*}$

\begin{tabular}{|c|c|c|c|c|}
\hline \multirow{2}{*}{$\begin{array}{l}\text { Oocyte } \\
\text { grade }\end{array}$} & \multicolumn{3}{|c|}{ Length of preincubation $(h)$} & \multirow[b]{2}{*}{ Total } \\
\hline & $2-5$ & $9-11$ & $21-29$ & \\
\hline I & $\begin{array}{c}4,6 \\
(n=2)\end{array}$ & $\begin{array}{c}4,5 \\
(n=2)\end{array}$ & $\begin{array}{c}7.5 \pm 1.4 \\
(n=8)\end{array}$ & $\begin{array}{l}6.6 \pm 1.0 \\
(n=12)\end{array}$ \\
\hline II & $\begin{array}{l}2.3 \pm 0.6 \\
(n=7)\end{array}$ & $\begin{array}{c}13.7 \pm 3.4^{b} \\
(n=7)\end{array}$ & $\begin{array}{c}9.3 \pm 1.0^{6} \\
(n=18)\end{array}$ & $\begin{array}{l}8.8 \pm 1.2 \\
(n=32)\end{array}$ \\
\hline III & $\begin{array}{c}1 \\
(n=1)\end{array}$ & $\begin{array}{c}1,8 \\
(n=2)\end{array}$ & $\begin{array}{c}7.6 \pm 1.1 \\
(n=10)\end{array}$ & $\begin{array}{c}6.6 \pm 1.1 \\
(n=13)\end{array}$ \\
\hline IV & - & $\begin{array}{c}1 \\
(n=1)\end{array}$ & $\begin{array}{c}6.5 \pm 1.7 \\
(n=4)\end{array}$ & $\begin{array}{l}5.4 \pm 1.7 \\
(n=5)\end{array}$ \\
\hline Total & $\begin{array}{c}2.8 \pm 0.6 \\
(n=10)\end{array}$ & $\begin{array}{l}9.6 \pm 2.5^{\mathrm{a}} \\
(n=12)\end{array}$ & $\begin{array}{c}8.3 \pm 0.6^{\mathrm{a}} \\
(n=40)\end{array}$ & $\begin{array}{c}7.7 \pm 0.7 \\
(n=62)\end{array}$ \\
\hline
\end{tabular}

*Where there were fewer than three embryos per group the maximum cell number of each embryo is shown, statistical comparisons were not performed when $n<3$.

d $P<0.001$ compared with $2-5 \mathrm{~h}$ preincubation (total).

${ }^{b} P<0.001$ compared with $2-5$ h preincubation (grade II only).

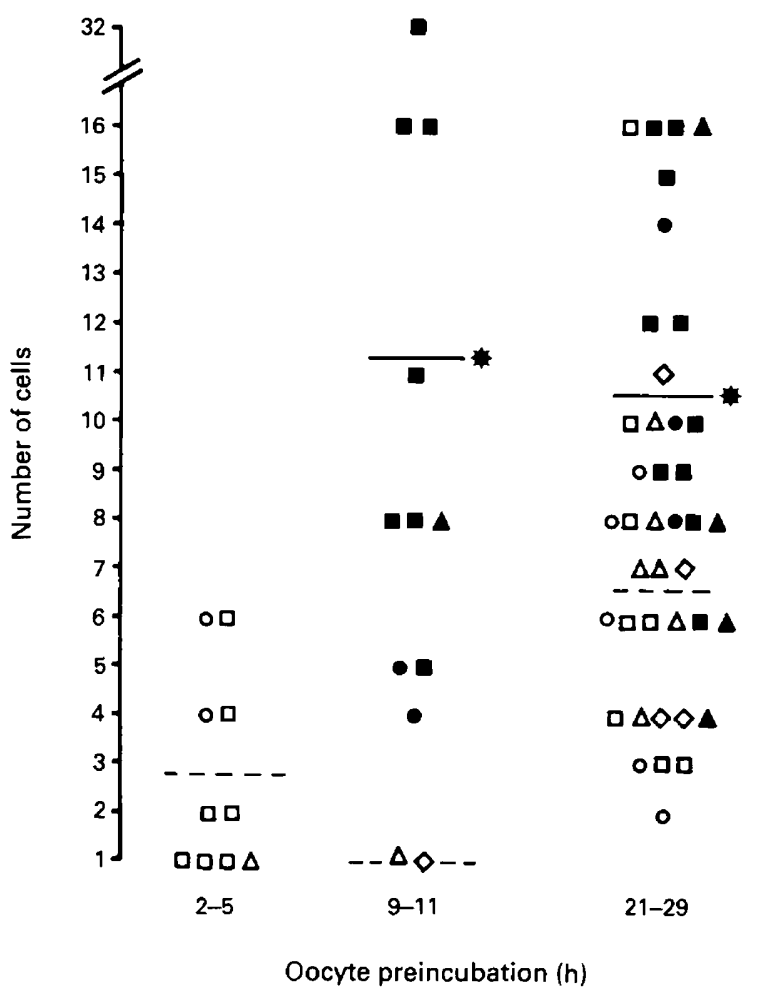

Fig. 2. Maximum cell number reached by each embryo according to oocyte grade and preincubation time. Non-delayed embryos (closed symbols); delayed embryos (open symbols); embryos developing from grade I $(\boldsymbol{O}, \bigcirc)$, grade II $(\boldsymbol{\square}, \square)$, grade III $(\boldsymbol{\Delta}, \Delta)$ and grade IV $(\diamond, \diamond)$ oocytes; mean cell number of delayed $(---)$ and non-delayed $\left(-\right.$ embryos. ${ }^{*} P<0.001$ compared with delayed embryos.
$62(56 \%)$ embryos were delayed on day 2 (Fig. 2). Delayed embryos reached a mean maximum cell number of $5.2 \pm 0.6$, which was significantly less than $10.8 \pm 1.1(P<0.001)$ cells in embryos that were not delayed (Fig. 2). All ten embryos developing from oocytes preincubated for only $2-5 \mathrm{~h}$ were delayed. Only 2 of $12(17 \%)$ oocytes preincubated for $9-11 \mathrm{~h}$ were delayed; however, 23 of $40(58 \%)$ embryos from oocytes that were preincubated for $21-29 \mathrm{~h}$ were delayed. When considering only embryos developing from oocytes preincubated for 21-29h, embryos that were not delayed on day 2 reached a significantly higher mean maximum cell number than delayed embryos ( $10.5 \pm 0.9$ versus $6.6 \pm 0.7, P<0.005$ ). This difference was independent of the maturity of the oocyte from which the embryo had developed. That is, the mean maximum cell number of delayed embryos was not significantly different whether the embryos had developed from grade I, II, III or IV oocytes (data not shown). This was also true for embryos that were not delayed (data not shown).

\section{Discussion}

The treatment protocol used to control the ovarian cycle and induce follicular maturation was highly successful. On all except one occasion follicles greater than $2 \mathrm{~mm}$ were present and were aspirated. No animals had ovulated at the time of laparotomy and the fertilization rate was high. This protocol is a modification of that reported by Lopata et al. (1988). They found that if cloprostenol was administered at 09:00 h on day 0 and hCG at $09: 00 \mathrm{~h}$ on day 7 , oocytes could be collected at laparotomy $24 \mathrm{~h}$ later but $67 \%$ were polyspermic after fertilization. If instead they administered hCG at 17:00 h on day 7, the polyspermy rate decreased but two of 14 animals had already ovulated at laparotomy. This indicates that the timing of hCG administration relative to cloprostenol is critical to the success of oocyte collection and normal fertilization. We have given hCG exactly halfway between the two times used by Lopata $e t$ al. (1988) and found that no animals had ovulated, the fertilization rate was high and the polyspermy rate very low.

It has previously been demonstrated that, in marmosets, most oocytes from follicles smaller than $2.5 \mathrm{~mm}$ are immature and cannot be fertilized normally (Lopata et al., 1988). Hence we only aspirated follicles that were greater than $2 \mathrm{~mm}$ and were able to recover an average of 2.1 oocytes per animal. Obviously, it would be advantageous to increase the number of oocytes produced by each animal. However, preliminary studies to superovulate the marmoset ovary with human menopausal gonadotrophin or clomiphene citrate have been unsuccessful (Harlow, 1984): there was no increase in the number of developing follicles. Moreover, other non-human primates develop antibodies to gonadotrophin preparations and become resistant to superovulation (Platia et al., 1984; Bavister et al., 1986; Dukelow and Vengesa, 1986; Rotten et al., 1986; Cranfield et al., 1989). Marmosets do not develop antibodies to hCG and can be used repeatedly for collection of pre-ovulatory oocytes.

Lopata et al. (1988) found that $61 \%$ of marmoset oocytes collected from follicles greater than $2.5 \mathrm{~mm}$ fertilized in vitro. In the present study, we have achieved a higher fertilization rate, $82 \%$, for all oocytes. Moreover, to our knowledge, we have achieved the highest consistent fertilization rate of any 
non-human primate species. In other species, fertilization rates in vitro range from $39 \%$ in the baboon (Fourie et al., 1987) to $71 \%$ in the cynomolgus macaque (Fujisaki et al., 1989). As expected, the fertilization rate was higher in more mature oocytes. However, when cultured for up to $29 \mathrm{~h}$ in vitro, grade III and IV oocytes continued to mature, as demonstrated by expansion of the cumulus cells. This in vitro maturation also increased the fertilization rate up to $100 \%$ in grade III oocytes. This demonstrates that nuclear maturation of marmoset oocytes will occur in culture. The fertilization rate of grade I and II oocytes was $100 \%$ after only $9-11 \mathrm{~h}$ preincubation and was not compromised by extended in vitro maturation for $21-29 \mathrm{~h}$.

Although a very high proportion of fertilized oocytes cleaved, the development of marmoset embryos in vitro was poor. On average, embryos developed to a maximum of 7-8 cells and only $11 \%$ reached 16 cells. In the only other published study of culture of in vitro fertilized marmoset embryos, only a small number of embryos were examined and $40 \%$ developed to the morula stage and $20 \%$ to the blastocyst stage using conditions and media similar to those described here (Lopata et al., 1988). The aim of our study was to culture in vitro fertilized marmoset embryos to advanced blastocyst stages and we have yet to determine whether embryos produced in our IVF system can develop into viable offspring. However, it has been demonstrated that in vitro fertilized marmoset embryos can develop in vivo and, when transferred to recipients at the four- to six-cell stage, $60 \%$ result in live births (Lopata et al., 1988). Preimplantation embryos of other non-human primates have also proved very difficult to culture in vitro (Boatman, 1987; Wolf et al., 1990; Morgan et al., 1991) with little development past the eight- to 16-cell stage (Lanzendorf et al., 1990).

We have found that the maximum cell number reached by marmoset embryos in vitro did not depend on initial oocyte maturity provided that the oocytes were preincubated for sufficient time. Thus, after $21-29 \mathrm{~h}$ preincubation, there was no difference in the mean maximum cell number between embryos derived from grade I and grade IV oocytes.

Oocyte preincubation time had a significant effect on embryo development. Embryos derived from oocytes preincubated for only $2-5 \mathrm{~h}$ developed to a mean maximum of only three cells, whereas oocytes preincubated for 9-11 h developed to an average of ten cells. There was no further advantage in preincubating oocytes for longer periods. This would suggest that although oocytes can attain nuclear maturity by longer preincubation times as demonstrated by the increase in fertilization rate, there is a limit to the extent of cytoplasmic maturity that can be achieved during in vitro culture. This is also true of rhesus oocytes (Boatman, 1987; Lanzendorf et al., 1990; Morgan et al., 1991).

Because the embryos in the present study developed poorly, we have been unable to ascribe cell cycle times and cleavage rates accurately. The only comparable data come from naturally fertilized embryos, flushed from the uterus, which suggests that marmoset embryos reach the four-cell stage on day 2 but after this developmental rates may vary. Morulae can be collected between days 5 and 7 and blastocysts between days 7 and 9 after ovulation (Harlow, 1984); hence comparisons with in vitro development particularly during later preimplantation stages must be made with caution. Some marmoset embryos in the present study continued to cleave slowly for up to 12 days. It is hoped that optimization of the in vitro culture of marmoset embryos will enable further characterization of their early development. However, we have been able to show that embryos that reached the four-cell stage at the expected time (i.e. day 2) developed significantly further than those that were retarded, suggesting that extended preincubation of oocytes has a detrimental effect on cytoplasmic maturity. We found that $83 \%$ of embryos derived from oocytes preincubated for 9-11 h reached the four-cell stage at the expected time but that only $43 \%$ of embryos derived from oocytes preincubated for $21-29 \mathrm{~h}$ were cleaving at the normal rate at the four-cell stage. Prolonged preincubation with resultant ageing of the oocytes may result in the inability of the cytoplasm to support normal cleavage. If true, it might be expected that the least mature oocytes would be affected to a lesser extent but this was not the case. Delayed cleavage, caused by prolonged oocyte preincubation, occurred to a similar extent in embryos derived from all four grades of oocyte. Another explanation is that the in vitro environment is supportive of oocyte maturation for approximately $10 \mathrm{~h}$ but after longer periods has an adverse effect on cytoplasmic factors that are responsible for early cleavage.

In all the experiments described here, we have used MEM supplemented with $10 \%$ serum as a culture medium, as this has previously been demonstrated to support marmoset preimplantation development in vitro, albeit using only a small number of embryos (Lopata et al., 1988). In macaques, simple salt media such as modified Tyrode's solutions supplemented with bovine serum albumin support embryo development during early cleavage stages but not morula formation (Boatman, 1987). Macaque embryos develop from the two-cell stage to at least the morula stage in a more complex media (Boatman, 1987) so we avoided, at least in our initial studies, culturing early cleavage stage marmoset embryos in simple media. However, having established an optimal system for marmoset IVF, we will now test alternative embryo culture techniques including different media and co-culture on oviduct and uterine epithelia.

This study was supported by a joint MRC/AFRC programme grant. We wish to thank T. Noble, D. Stula and C. Walker for care of the animals and $\mathrm{A}$. P. F. Flint for critically reading the manuscript.

\section{References}

Balmaceda JP, Pool TB, Arana JB, Heitman TS and Asch RH (1984) Successful in vitro fertilization and embryo transfer in cynomolgus monkeys Fertility and Sterility 42 791-795

Bavister BD, Boatman DE, Liebfried L, Loose M and Vernon MW (1983) Fertilization and cleavage of rhesus monkey oocytes in vitro Biology of Reproduction 28 983-999

Bavister BD, Dees C and Schultz RD (1986) Refractoriness of rhesus monkeys to repeated ovarian stimulation by exogenous gonadotrophins is caused by non-precipitating antibodies American Joumal of Reproductive Immunology and Microbiology 11 11-16

Boatman DE (1987) In vitro growth of non-human primate pre- and periimplantation embryos. In The Mammalian Preimplantation Embryo: Regulation of Growth and Differentiation in vitro pp 273-308 Ed. BD Bavister. Plenum Press, NY

Boatman DE, Morgan PM and Bavister BD (1986) Variables affecting the yield and developmental potential of embryos following super-stimulation and in vitro fertilization in thesus monkeys Gamete Research 13 327-338

Cranfield MR, Schaffer N, Bavister BD, Berger N, Boatman DE, Kempske S, Miner N, Panos M, Adams J and Morgan PM (1989) Assessment of oocytes 
retrieved from stimulated and unstimulated ovaries of pig-tailed macaques (Macaca nemestrina) as a model to enhance the genetic diversity of captive lion-tailed macaques (Macaca silenus) Zoo Biology (Supplement 1) 33-46

Dukelow WR and Vengesa PN (1986) Primate models for fertilization and early embryogenesis. In Primates: The Road to Self-Sustaining Populations pp 445-461 Ed. K Benirschke. Springer-Verlag, NY

Dukelow WR, Chan PJ, Hutz RJ, Demayo FJ, Dooley VD, Rawlins RD and Ridha MT (1983) Preimplantation development of the primate embryo after in vitro fertilization Journal of Experimental Zoology 228 215-221

Fourie FR, Snyman E, van der Merwe JV and Grace A (1987) Primate in vitro fertilization research: preliminary results on the folliculogenic effects of three different ovulatory induction agents on the chacma baboon, Papio ursinus Comparative Biochemistry and Physiology A 87 889-893

Fujisaki M, Suziki M, Kohno M, Cho F and Honjo S (1989) Early embryonal culture of the cynomolgus monkey (Macaca fasicularis) American Journal of Primatology 18 303-313

Harlow CR (1984) Endocrine and morphological aspects of pre-implantation development in the marmoset monkey (Callithrix jacchus jacchus) $\mathrm{PhD}$ thesis, University College London, University of London

Harlow CR, Shaw HJ, Hillier SG and Hodges JK (1988) Factors influencing follicle-stimulating hormone-responsive steroidogenesis in marmoset granulosa cells: effects of androgens and the stage of follicular maturity Endocrinology 122 2780-2787

Hodges JK, Green DI, Cottingham PG, Sauer MJ, Edwards C and Lightman SL (1988) Induction of luteal regression in the mamoset monkey (Callithrix jacchus) by a gonadotrophin-releasing hormone antagonist and the effects on subsequent follicular development Joumal of Reproduction and Fertility $\mathbf{8 2}$ $743-752$

Gould KG (1983) Ovum recovery and in vitro fertilization in the chimpanzee Fertility and Sterility 40 378-383

Irsigler UM, van der Merwe JV and Botes AD (1984) Fertilization and cleavage in vitro of baboon oocytes South African Medical Journal 66 447-450
Lanzendorf SE, Zelinski-Wooten MB, Stouffer RL and Wolf DP (1990) Maturity at collection and the developmental potential of rhesus monkey oocytes Biology of Reproduction 42 703-711

Lopata A, Summers PM and Hearn JP (1988) Births following the transfer of cultured embryos obtained by in vitro and in vivo fertilization in the marmoset monkey (Callithrix jacchus) Fertility and Sterility 50 503-509

Morgan PM, Boatman DE and Bavister BD (1990) Relationships between follicular fluid steroid hormone concentrations, oocyte maturity, in vitro fertilization and embryonic development in the rhesus monkey Molecular Reproduction and Development 27 145-151

Morgan PM, Warikoo PK and Bavister BD (1991) In vitro maturation of ovarian oocytes from unstimulated rhesus monkeys: assessment of cytoplasmic maturity by embryonic development after in vitro fertilization Biology of Reproduction 45 89-93

Platia MP, Bloomquist G, Williams RF and Hodgen GD (1984) Refractoriness to gonadotrophin therapy: how to distinguish ovarian failure versus pseudoovarian resistance caused by neutralizing antibodies Fertility and Sterility $\mathbf{4 2}$ 779-784

Rotten D, Laherty RF, Monroe SE and Jaffe RB (1986) Induction of ovulation in the post-partum rhesus monkey: factors determining success in obtaining primate luteal tissue Fertility and Sterility 45 859-866

Summers PM, Wennink CJ and Hodges JK (1985) Cloprostenol-induced luteolysis in the marmoset monkey (Callithrix jacchus) Journal of Reproduction and Fertility 73 133-138

Summers PM, Shephard AM, Taylor CT and Hearn JP (1987) The effects of cryopreservation and transfer on embryonic development in the common marmoset monkey, Callithrix jacchus Journal of Reproduction and Fertility 79 $241-250$

Wolf DP, VandeBoort CA, Meyer-Haas GR, Zelinski-Wooten MB, Hess DL, Baughman WL and Stouffer RL (1989) In vitro fertilization and embryo transfer in the rhesus monkey Biology of Reproduction 41 335-346

Wolf DP, Thomson JA, Zelinski-Wooten MB and Stouffer RL (1990) In vitro fertilization - embryo transfer in non-human primates: the technique and its applications Molecular Reproduction and Development 27 261-280 